NOTA BIBLIOGRAFICA

\title{
Geología de la Región de Tampico
}

Fơr John M. Muir (1)

Extracto de L, B. Kelium

Aunque este libro se ocupa especialmente de la Geología del Embayment de Tampico, el objetivo del autor es el de mostrar los campos petrolíferos de esa área, dentro del cuacixo de la historia geológica de México.

Como en el campo de investigación de los terrenos petro= lifferos ha habido serias controversias y diferencias de opinión, en lo que se refiere a la interpretación estructural y estratigráfica, el autor presenta y analiza les ideas de las diversos investigadores y él mìsmo expone sus propias conclusiones, basadas en un plan lógico, cuando esto es posible, o arbitrario, en easos en que los datos son insuficientes. Sin tmbargo, sus conclusiones están siempre apoyadas en un largo contacto con esos problemas geológicos y basadas en las mejores fuentes de información.

El libro se recomienda, no solamente por el análisis y la reinterpretación de los primeros trabajos publicados, sinu también por lo extenso de los nuevos y precisos datos que contiene, recogidos direetamente por el autor duxante sus estudios en el campo y en el Iaboratorio, con la cooperación de numerosos geólogos, familiarizados cada uno con determinadas partes de la área de Tampico, asi como con los paleon-

(1) "Geology of the Tampico Region, Mexico", by John M. Muir. 246 páginas, 41 figurats, 15 láminas y 9 tablas. Publicación especial de la American Association of Petroleum Geologists. Tulsa, Otlahoma, 1936.
Traducido al español por. E. Ordónez. 
tólogos que han estudiado las microfaunas, en muestras colectadas por el autor.

El libro de Muir es una obra de gran autoridad, escrito por un experto y que se ocupa de una región que ha sido de las más productoras de petróleo del mundo.

La excelente carta geológica del Embayment de Tampico, así como los mapas estructurales de los campos ptrolíferos que van insertos en el libro, son significativas contribuciones a la Geología de México, lo mismo que las extensas listas de faunas de localidades precisas de cada formación. Los que se dedican a la Historia de la Tierra, recibirán son agrado este libro, pues que les permitirá correlacionar ciertos acontecimientos geológicos de México, con el panorama geológico del resto del mundo.

La obra de Muir comienza con una introducción, escrita por L. W. Stephenson, de la United States Geological Survey, seguida de un prefacio del autor del libro. saber:

Muir divide su exposición en cuatro grandes partes, a

1.-Introducción.

II.-Estratigrafía y Paleogeografía.

III.-Rocas ígneas y manifestaciones superficiales de petróleo.

IV.-Caracteres Generales Estructurales y Estructura de los campos petroliferos.

En seguida viene un apéndice, una bibliografía y por, último, una lista de los mapas que acompañan al texto.

En la parte primera, se expone brevemente el descubrimiento y los acontecimientos principales que tuvieron lugar durante el desarrollo de los campos petrolíferos de toda la región de Tampico y la descripción de la topografía y drenaje de la llanura costera del Golfo de México.

La segunda parte comienza con la descripción de las rocas paleozoicas y con el estudio de una sección del Mississipiano y del Pérmico medio, de la Sierra de Peregrina, $11 \mathrm{kj}$ lómetros al N. W. de Ciudad Victoria, Tamps. Esta localidad 
queda en el margen del Embayment de Tampico, siendo la más próxima a los campos petroleros de esta zona en la que hay sedimentos paleozoicos bien determinados. En este bosquejo de la sección de Peregrina, que ha sido revisado por Arnold Heim, se hace referencia a la existencia del gneiss, en la base; cubierto de estratos del Missisipiano, Pérmico, Triásico, Jurásico y Cretácico. El Mississipiano está en contacto con el gneiss, a lo largo de una falla y tanto las capas del Triásico, superpuestas al Pérmico, como las del Jurásico, ncima del Triásico, están separadas por discordancias anguiares respectivamente. De la obra de Burckhardt está tomada una tabla y la descripción de las rocas del Liásico de la Huasteca veracruzana y del Estado de Puebla, mostrando sus fósiles marinos, en asociación con algunas plantas terrestres. El Jurásjco superior, aparece en transgresión sobre el Lias.

También se mencionan muchas localidades en las que el Iurásico superior, aparece en las montañas que limitan el Embayment de Tampico, con los detalles que se han obtenido de cada localidad. En tres sitios de la Sierra Madre Oriental, se ha encontrado el Jurásico superior, reposando con discordancia sobre los "Red Beds" del Permo-Triásico. En tres pozos de los perforados al N. W. de Tampico, se ha encontrado el Jurásico, a 974 m., 983 m. y 1108 m. de profundidad respectivamente.

Lo mismo que la han descrito los antiguos autores, el de este libro describe la estratigrafía del Cretácico bajo nombres europeos, como sigue:

\begin{tabular}{|c|c|c|}
\hline Cretácico & Superior.. & $\left\{\begin{array}{l}\text { Maestrichtiano, } \\
\text { Campaniano. } \\
\text { Santoniano. } \\
\text { Conaciano. } \\
\text { Turoniano. }\end{array}\right.$ \\
\hline Gretâcico & Medio..... & $\left\{\begin{array}{l}\text { Cenomaniano. } \\
\text { Albiano. }\end{array}\right.$ \\
\hline Cretâcico. & Inferior... & $\left\{\begin{array}{l}\text { Aptiano. } \\
\text { Neocomiano. }\end{array}\right.$ \\
\hline
\end{tabular}


Capas der Cretácico inferior, han sido identificadas en dos pozos en los campos petrolíferos del N. W. de Tampics, siendo las mismas que afloran en la Sierra de San Carlos de Tamaulipas y en la región de Huayacocotla, Ver.

El Cretácico medio en la región de Tampico, está desarrollado en dos facies; una facies de arrecife, llamada "Caliza del Abra" y la otra facies de agua profunda, llamada "Caliza de Tamaulipas".

El libro trae un bosquejo, que muestra la đistribución de estas dos facies, tanto en el interior, como en las márgenes del Embayment de Tampico. También se mencionan los fósiles, que de tiempo en tiempo se han encontrado en estas calizas por diversos geólogos, siendo la compilación de faunas de estas dos facies, la mejor que se ha hecho hasta ahora.

Muir emplea el término "Otates" para designar un horizonte de margas apizarradas (shales) fosiliferas, que se encuentra en una zona de la base del Albiano, de la caliza de Tamaulipas, to que permite establecer una división superior $\mathbf{y}$ una inferior de dichas calizas.

El horizonte "Otates" de Muir, está muy extendida en el Norte de México, siendo el mismo al que los autores antiguos llamaron el horizonte de "Clansayes". Muir considera las calizas albiano-cenomanianas del cañón de la Borrega, en Ia Sierra de Tamaulipas, como la sección tipo de la parte siperior de la caliza de Tamaulipas. En los campos petroleros del N. W. y W. de Tampico, el horizonte de Otates se encuertra de $\operatorname{los} 428$ a los 680 pies, abajo de la cima de la caliza de Tamaulipas.

En dos pozos, uno en Cuahuayotes y otro en Lagartero, este horizonte tiene solamente 12 y 70 pies de espesor, respectivamente. La figura II-A de la obra, es un mapa isopaco, que muestra las variaciones en espesor, de la parte su* perior de la caliza de Tamaulipas.

Con excepción de una sola localidad, las capas del Cre. tácico superior están concordantes con la caliza de Tamaulipas, hasta donde ha siflo posible observar este contacto. Sin embargo, en muchos lugares hay una discordancia entre la 
caliza del Abra y las capas del Cretácico superior que las cubren.

Lo mismo que Stephenson, Muir llama "Agua Nueva", a un grupo de capas de edad turoniana y cenomaniana strperior, las que $\operatorname{los}$ antiguos autores habian considerado como San Felipe inferior. Por Io tanto, el autor limita el término "San Felipe", a las capas de edad coniaciana y santoniana inferior. Movimientos diferenciales en el fondo del mar, durante el Turoniano, se consideran como las causas probables del aumento en espesor de la formación Agua Nueva en los sinclinales. Por otra parte, parece que hay un adelgazamientc regional de dicha formación, de Norte a Sur.

Es dudoso que en los campos del Sur de Tampico exista la formación de Agua Nueva. En los pozos de estos campos petroliferos, las formaciones de Agua Nueva y San Felipe podrían distinguirse solamente por su litología.

Algunas bandas de cenizas volcánicas verdes, en la parte inferior de Agua Nueva, persisten en una grande área $y$ se utilizan como un horizonte.

Una zona alterada de toba volcánica, de color lila, separa la parte superior, de la inferior de San Felipe. La parte superior de San Felipe, en los campos del N. W. y W. de Tamjico, está principalmente compuesta de capas alternantes de caliza y de margas apizarradas. Existe una facie más cal. cárea en los campos del Norte y una fácie más areillosa en los campos del Sur. Lechos de bentonita se presentan a diterentes niveles en San Felipe superior. En los campos del Sur, las capas de San Felipe forman un conjunto delgado y discordante sobre la caliza del Abra, habiendo en el contacto un conglomerado de brecha "breccia conglomerate".

Durante el período de tiempo del Turoniano al Campaniano, se depositó en una gran área de la Sierra Madre, al Oeste del Embayment de Tampico, una caliza de facie de arrecife y es la que se denomina "Caliza de Tamasopo" y es en parte equivalente a la formación Agua Nueva y mientras que en el Este de México se depositaban las capas de Mén- 
diez y San Felipe, hacia el Oeste, en lo que es hoy Sierra Madre, se depositaba la caliza de arrecife de Tamasopo.

El Santoniano superior, el Campaniano y el Maestrichtiano representan lo que se ha llamado, las capas de Méndez - las margas apizarradas de Méndez, las cuales tienen en los pozos, hasta mil pies de espesor. Estas capas, en un espesor de veinte a treinta pies, son de un rojo característico, en la cima de la formación. Las capas de Méndez contienen abundantes foraminíferos $y$ en algunas localidades también contienen rudistas. En la superficie de esta formación, existe una discordancia erosional, marcada por irregularidades, y las depresiones están llenas de arenas, en la base de la formación Tamesi. Más allá de la área de los campos petrolíferos, hay una facies acuosa, de edad maestrichtiana, equivalente en parte a Méndez superior, y así octrre por ejemplo: en la región de Cárdenas-Canoas, S. L. P.; al Oriente de Villa Guerrero, en el mismo Estado, y por último, al Sur del rio Sta. Clara, en el Sur de Tamaulipas. Lechos delgados de reniza volcánica se ven entre las capas de Méndez. En los pozos del campo petrolero de Ebano, hay delgadas capas de caliza intercaladas entre las margas apizarradas de Méndez, desde la base de esta formación, hasta como 300 pies abaj! de la cima de la formación.

La transición de las capas del Cretácico, a las del Eoceno. se manifiesta en la formación llamada "Tamess" y son de edad Daniana? Muir revisa y analisa cuidadosamente la controversia relativa a la formación "Velasco", "Tamesi" n "Chicontepec". Como no se ha designado previamente una localidad tipo para la formación Tamesí, el àutor la propone on los afloramientos que se ven en la ribera Oeste del rio Tamesí, en el lugar llamado Tantoyuquita, en la parte Oriental de la hacienda del Naranjo, Tamps., y agrega la lista de los foraminíferos encontrados en esta localidad y descritos por" Cushman. La palabra "Velasco". Ia rechaza de plano el autor de este libro, quedando el grupo de capas de la formación Chicontepec, como del Eoceno.

Al Sur del sitio conocido con el nombre dę Crucero, en 
el Oriente del Estado de San Luis Potosí, la formación Tamesí cambia de su facies de marga apizarrada (shale), a lo que se llama "Flysch"; pero el autor no define específicamente tal término, ni describe la evidencia de la facies flysch, diciendo solamente que en aquella localidad hay areniscas intercaladas en las margas y que la estratificación está muy dislocada (disturbed).

Tomando en su mayor parte de la obra de Burckhardt, el autor del libro que se viene extractando, incluye un sumario de la paleogeografía mesozoica y un mapa de los mares mesozoícos. Se describen también los movimientos epeirogénicos que tuvieron lugar a fines del Triásico, lo que originó extensos depósitos continentales y la creación de dos cuencas con sedimentación marina, una en el Norte de Sonora y la otra en extensa región de los Estados de Oaxaca, Guerrero, Puebla y Vlexacruz.

Grandes mares, muy poco variables en área, cubrieron la mayor parte de lo que hoy es México, durante el Jurásico superior y el Cretácico inferior. Dichos mares estuvieron borreados por amplias tierras firmes en el oeste y también en Texas y hacia el noreste de México. Durante el Aptiano superior, (Cretácico) hubo transgresión marina hacia el Noreste, invadiendo estas últimas tierras.

Los movimientos epeirogénicos en el oeste y sur de México, de principios del Cretácico medio, (Albiano inferior) se reflejaron en él centro y oriente del país, dando lugar a la formación de una zona de margas apizarradas del horizonte de Clansayes o zona de Otates y también por arrecifes del Cretácico medio (caliza del Abra), dispurestos en forma de anchos pliegues o flexuras que formaban crestas submarinas. Los mares del Cretácico medio, que ocuparon la mayor parte del este y sur de México, comenzaron a retirarse hacia fines de ese período. Esta trangresión fué seguida de un avance temporal hacia el sur, durante el Turoniano, pero posteriormente la retirada del mar continuó aun durante el Cretácico superior. Hacia el fin del Maestrichtiano hubo una emergencia temporal que abarcó una grande área y que dió lugax al 
hiatus Méndez-Tamesí. La sumersión que se verificó durante el Daniano, no fué muy grande, toda vez que existieron muy grandes islas en la área que es hoy la costa oriental de México.

Se ha establecido para el Embayment de Tampico, el siguiente orden de formaciones terciarias:

6.-Formación Túxpan.............. Mioceno Inferior.

5.- $\quad$ Mesón............. Oligoceno Medio.

4.- $" \quad$ Huasteca. . . . . . . . . .... Oligoceno Inferior.

3.- " Chapopote............ Eoceno Superior.

2.- $\quad " \quad$ Tempoal............. Eoceno Medio.

1.-Grupo Chicontepec. .

Capas de la formación Aragón.
Formación Tanlajás.

En la localidad típica de la formación Aragón, se ve la influencia marina en la parte más alta de las capas de Chicontepec $y$ son probablemente equivalentes en edad a las de Wilrox, en la costa del Golfo en Texas. La formación Guayabal, descrita por otros autores, Muir la coloca en la parte superior de la formación Tempoal. Esta formación, en el Embay. ment de Tampico, no tiene menos de 1600 pies de espesor y es equivalente en edad a la formación Cook Mountain; de la costit de Texas. La formación Chapopote, incluye las capas del Eoceno superior, llamadas Alazán por los autores antiguos y representa la facies de influencia marina de las capas de Tantoyuca.

El autor propone el nombre de formación "Huasteca" para las capas del Oligoceno inferior que habían sido incluídas anteriormente en la formación Alazán. Como las capas deI Eoceno y Oligoceno existen en Ia localidad típica de Alazán y como este último nombre ha sido usado por algunos auto. res para designar capas del Eoceno y por otros para capas ¿el Oligoceno, se pensó que un nuevo nombre aclararía esta confusión, que había resultado únicamente del uso ambiguo 
del término. La localidad tipo de la formación Huasteca $\Leftrightarrow \beta$ la de Paso de Comales, lugar que se halla en donde el río de Comales cruza el camino de Ozuluama a Tantoyuca. En Ios campos petroleros del Sur, la formación Huasteca adquiere un espesor hasta de 2200 pies $y$ cubre a restos de la formacín Tempoal y Tamesi y aún en algunos casos descansa directamente sobre la caliza del Abra.

La formación Mesón, en algunos lugares, está en prasición concordante con la formación Huasteca y en todas partes se sobrepone a horizontes inferjores de esta formación. Mesón incluye las capas que llamó Dumble, de San Fernando y San Rafael. El Oligoceno superior puede que exista al norte y oeste đe Papantla, Ver. La formación Túxpan, del Mioceno inferior, está en concordancia con horizontes inferiores o más antiguos.

La historia geológica del Embayment de Tampico se re. laciona íntimamente con la retirada del mar al este durante el Eoceno, pero con oscilaciones en la línea del litoral, domì mínando Ia regresión durante el Olígoceno y Wioceno. Los movimientos orogénicos creadores de la Sierra Madre Orienta?, comenzaron durante el Eoceno, a principios de Wilcox, durando hasta el principio del Mioceno.

El tiempo post-terciario está representado por capas no movidas de Ostreas, cerca del nivel del mar y aun en regiones mâs elevadas de la costa, consistiendo de caliches y de conglomerados gruesos de caliza cubriendo a las formaciones cretácicas y Terciarias y por depósitos de aluvión hasta de 250 pies de espesor en la parte baja de las vegas de los ríos.

La parte III del libro de Muir, se ocupa de la distribución y de Jos tipos de rocas ígneas conocidos en la region de Tampico y de las manifestaciones superficiales de gas y petxóleo que existen en esa área.

Las regiones en las que dominan jas rocas ígneas, son: una al oriente de la Sierra de Tamaulipas y la otra, la Siera de Tantima, en el norte del Estado de Veracruz. La primera consiste en su mayor parte de tobas y lavas basâlticas, habiendo varios conos volcánicos; en la segunda se encuen- 
tran dioritas y lavas y diques de basalto. El Bernal de Hor. casitas, cerca de Magiscatzin, Tamps. se le considera como un enorme tapón de lava, levantado a 700 metros de su chimenea, después de la formación de un casquete de lava.

Algunos bloques de granito desparramados al pié del tapón, se supone que fueron lanzados de las profundidades. Numerosos tapones de lava se ven diseminados en todos los campos petroleros. El libro trae una breve descripción petrográfica de las rocas de la región de San José de las Rusias, en el sureste de Tamaulipas, hecha por H. H. Thomas.

En algunos de los pozos de los campos petrolíferos se han encontrado basaltos, dioritas y gabros. El basalto es la roea intrusiva más común.

En la Sierra de San Carlos y en la Sierra de Tamaulipas, situadas respectivamente en el centro y sur de este Estado, se encuentran sienitas de nefelina, dioritas; basaltos y diques de diversas rocas.

Las filtraciones naturales de petróleo se agrupan en tres elases: de asfalto, de petróleo pesado y de gas, siendo muy abundantes, tanto en los campos petroleros de] norte, como en los del sur y aún en San José de las Rusias (también en la región de Papantla) y aun en donde no se ha encontrado petróleo comercial en los fozos, como en los que se han perforado en San José de las Rusias. DeGolyer ha examinado centenares de filtraciones y dice que se encuentran en aquelias regiones por millares. De una manera general puede decirse nue estas filtraciones están asociadas con basaltos en diques, pero otras ocurren en fallas, pliegues y a través de capas muy paradas o muy inclinadas.

En la parte IV, Muir presenta un resumen general de la estructura del Embayment de Tampico y de las sierras que Jo limitan. A continuación da una descripción detallada de cada yacimiento o pool de petróleo de los campos del Norte ¿́sí como de los campos del Sur. Desde el punto de vista geoiógico, la descripción que se da en este libro, de los campos petroleros, es la más extensa y comprensiva que se ha hecho 
hasta ahora. Esta descripción viene acompañada de un mapa que muestra la situación de cada campo productor del Norte y el lector puede orientarse fácilmente al leer la des. cripción de cada pool. Trae también un mapa del subsuelo con las curvas de nivel que muestran la configuración de la caliza de Tamaulipas y otro de los campos del Sur con las cur. vas de nivel de la caliza del Abra. La estructura particular. de varios pools se muestra un detalle en figuras separadas.

La estructura de la Sierra Nadre se explica como una serie de montañas anticlinales orientadas del N. W. al S. E. Estos anticlinales son generalmente asimétricos, con el plano axial echado unas veces al W. y otras al $\mathrm{E}$. Las sierras marginales de la Sierra Madre, hacia el E., son más bien pliegues simples que pliegues acostados. Fn la sierra frontal, llamada Sierra del Abra, el anticlinal es asimétrico, con ei flanco dei $E$. muy inclinado. Varias fallas locales se advierten en este flanco. Pliegues encimados en la Sierra Madre Oriental, han sido citados por varios geólogos. AI norte de Cómez Farías, Tamps. con cinco agudos pliegues, que forman otras tantas crestas, comienzan la sierra frontal del Abra y aśi continúa hacia el norte, más allá de Ciudad Victoria. Muir asienta, que la presión que causó estos plegamientos procede del aeste, con disminución de intensidad hacia el oriente.

Buen número de pequeñas sierras y aristas anticlinales se levantan en la llanura costera del Golfo, al este de la Sierra Madre Oriental. En algunas de éstás, el echado de las capas en los flancos es suave, pero en otras llega hasta tetser 40 grados. En algunas otras, el echado normal suave resulta más inclinado debido al empuje de rocas intrusivas.

Los campos petroíf́feros del Norte, están situados sobre la prolongación sur de la sierra de Tamaulipas y este plegamiento es considerado como de muy profundo origen y vertical en sus efectos. Los horizontes productores en estos campos son: la caliza de Tamaulipas, la formación de Agua Nueva y las rocas de San Felipe. La porosidad de las rocas que contienen el petróleo es secundaria y ha sido facjlitada por 
fallas, por agrietamientos y por los planos de juntura de las calizas. En los pozos de competencia, (offset wells) varía mucho la profundidad de donde procede el petróleo. Un pozo situado a bajo nivel, en el flanco de un anticlinal, puede alcanzar producción de un nivel más alto que un pozo situado sobre la cresta del mismo anticlinal. La invasión del agua salada, en estos campos, no avanza uniformemente.

Hasta Dic. 31 de 1934, los campos del Norte habian producido 705.000,000 de barriles de petróleo, habiendo sido perforados hasta esa fecha, 4254 pozos, de los cuales, solamente 1483 fueron productivos. En esa lecha, 595 pozos producían un promedio de 55 barriles por pozo, al día.

Los campos del Sur están situados sobre una cresta sejultada, en la que la principal deformación tuvo Iugar probablemente no después del Eoceno superior. El curso de esta cresta se divide en dos partes, una al sur, correspondiendo a la dirección de la Sierra Madre o de la sierra de Tamaulipas $\mathrm{y}$ otra al norte, que tiene un curso noreste. De un modo general, esta cresta consiste de un anticlinal asimétrico, con el flanco oeste más parado. Los diferentes sectores de producción de esta sierra sepultada, están separados por sillas estructurales y por lo menos, en un lugar, posiblemente por un graben o por un block hundido entre dos fallas.

Desde el sur de Amatián, hacia el norte, el flanco orien: tal del pliegue es bastante uniforme, pero en Cerro Azul y desde Tierra Blanca, hacia el sureste, rumbo a Alamo, la cresta del anticlinal es doble, y el flanco oriental del gran pliegue se encuentra erizado de varios pliegues menores. Al sur de Alamo, el pliegue anticlinal desaparece.

El horizonte productor en los campos del Sur, es la caliza del Abra. Su porosidad es debida a cavidades de fósiles, a disolución de la caliza, a fracturas y a fallas. La caliza, como se ha dicho, es de origen de arrecife y en partes ésta aparece como una brecha de conchas fósiles. Hasta Dic. 31 de 1934, Tos campos del Sur habían producido 986.750,000 barriles de petróleo. Solamente tres pozos produjeron la cuarta parte de este total. Hasta esa fecha, en los campos del 
Sur se habían perforado 1002 pozos, de los cuales 523 fueron productores: Durante el año de 1934, 246 pozos, ya en plena declinación, dieron un promedio de producción de 2975 barriles de petróleo por pozo, al día.

Un largo apéndice de este libro contiene las cifras de temperaturas del petróleo a boca de pozo, copiadas en su mayor parte de un artículo publicado por DeGolyer en 1917. Trae también las presiones de los pozos; la práctica de redusir la producción para impedir la presencia del agua salala; la de dinamitar los pozos, su tratamiento por el ácido y por último, la estratigrafía, obtenida por la columna de muestras de cada pozo.

El libro contiene al fin una excelente Bibliografía con 210 referencias.

Muchos geólogos, familiarizados y expertos en determihados campos petrolíferos de la región de Tampico, no están enteramente de acuerdo con las conclusiones del autor de este libro. Kellum, el autor de este extracto, por ejemplo, cree gue no hay pruebas que justificuen la aserción hecha en la pág. 150 del libro, de que la presión que causó el plegamiento ae la Sierra Madre Oriental vino del oeste. Al contrario, él opina que el flanco oriental de la sierra frontal del Abra es el frente de una masa comprimida por empuje del este. La aparente disminución de intensidad del plegamiento, hacia el éste de la Sierra Madre Oriental y que Muir cita como prue: ba de que el empuje, causa de los plegamientos, vino del oeste, es debida a que se redujo el esfuexzo de presión por el pliegue encimado que ereó la sierra del Abra. Que la intensidad del piegamiento no decreció hacia el este, se comprueba en el canón del río Guadalejo, en Gómez Farías, Tamps. en donde se pueden ver agudós y robustos pliegues al este, seguidos de capas en posición casí horizontal, en la prolongación nor$t_{t}$ de las sierras del Abra y de Tanchipa.

La cresta anticlinal de los campos del Sur queda como a 25 kilómetros más lejos de las sierras frontales de la Sierra Madre de lo que está a lo que Kiellum llama el "Arco Pánuco-. Sierra de Tamaulipas", de los campos del Norte. La primera, 
evidentemente se define como una área positiva durante el Cretácico medio ; pero no hay indicación clara de que el llamado Arco fué levantado antes del Cretácico superior. La estructura de is cresta anticlinal de los campos del Sur y de las sierras frontales al oeste, es enteramente diferente de la estructur: Pánuco-Sierra de Tamaulipas y de las sierras frontales al oeste. A juicio de Kellum, es temerario asegurar que la condición de esos grandes pliegues es la misma con relación a la Sierra Madre Orientai

Otro punto en el que Kellum difiere de Muir en el de la supresión del término Alazán para substituírlo por el de Huasteca, fundándose en que su uso introduce confusión al designar formaciones del Eoceno u Oligoceno y porque la localidad tipo de Alazán está afectada de grande erosión. Una solución mejor habría sido, la de retener el término Alazán imitándolo, ya fuese a capas del Eoceno superior, ya fuese a capas del Oligoceno inferior y escoger una nueva localidad típica de Alazán, (sensu stricto). Por otra parte, Muir hizo muy bien al poner en claro la confusión en el uso del término Alazán, pero la creación de un nuevo término, para sustituir el antiguo, no parece necesario.

El plan del libro de Muir puede quedar expuesto a la erítica de traer muchas notas al pié de las páginas, además de muchas citas entre paréntesis que interrumpen o desvían la atención del lector.

El estilo del libro habria resultado más sencillo, si el autor en lugar de presentar tantas citas textuales de otros autores, hubiera analizado los resultados a que llegaron esos autores.

Los lectores no familiarizados con la geografía de México, hallarán dificultades para encontrar las localidades cicadas en el libro, puesto que muchas no aparecen en los mapas y porque falta descripción más detallada de esas localidades.

Debe decirse que toda crítica de un libro, como el de Muir, no resulta excepcional, pues no es posible que personas conocedoras del mismo asunto acepten totalmente sus 
ideas. Aun teniendo en cuenta las diferencias de opiniones tanto en la interpretación de los resultados como del estilo, liay que confesar, que el libro de Muir trae gran riqueza de material hábilmente acumulado y presentado en forma saiisfactoria y que los geólogos que han trabajado en México y que han contribuído indirectamente a la formación de este libro, quedarán satisfechos de esta buena síntesis, hecha por un autor debidamente calificado por sus vastos conocimientos, como lo es John M. Muir. 